\title{
Tatalaksana Kraniektomi Dekompresif pada Pasien Cedera Otak Traumatik Berat yang Disertai Peningkatan Tekanan Tinggi Intrakranial Menetap
}

\author{
Fitri Sepviyanti Sumardi*), Hamzah ${ }^{* *}$, Sri Rahardjo $\left.{ }^{* * *}\right)$, Tatang Bisri****) \\ ${ }^{*}$ Departemen Anestesiologi \& dan Departemen Bedah Saraf Henan Provincial People's Hospital-Fakultas \\ Kedokteran Universitas Zhengzhou, ${ }^{* *}$ Departemen Anestesiologi \& Terapi Intensif Fakultas Kedokteran \\ Universitas Airlangga-RSUD Dr. Soetomo Surabaya, ${ }^{* * *}$ Departemen Anestesiologi \& Terapi Intensif Fakultas \\ Kedokteran Universitas Gadjah Mada-RSUP Dr. Sardjito Yogyakarta, ${ }^{* * * *}$ Departemen Anestesiologi \& Terapi \\ Intensif Fakultas Kedokteran Universitas Padjadjaran-RSUP Dr. Hasan Sadikin Bandung
}

\begin{abstract}
Abstrak
Tekanan tinggi intrakranial menetap adalah penyebab kematian terbesar pada pasien dengan cedera kepala traumatik berat. Pada cedera kepala berat, tatalaksana secara konservatif dan operatif dilakukan untuk meminimalisir terjadinya cedera otak sekunder. Peningkatan tekanan intrakranial biasanya disebabkan karena edema otak, hal ini sangat penting dan menentukan hasil luaran pasien/Glasgow outcomes scale (GOS) atau Extended GOS (GOSE). Data klinis menunjukkan bahwa kraniektomi dekompresif menurunkan angka kematian, meningkatkan fungsi pemulihan, menurunkan durasi perawatan di ICU dan meningkatkan hasil luaran berdasarkan Barthel Index Score. Kraniektomi dekompresif sering dilakukan sebagai penyelamatan empiris untuk melindungi kerusakan otak lebih lanjut akibat efek edema dan hipertensi intrakranial menetap. Konsep utama tatalaksana pasien dengan tekanan tinggi intrakanial yang menetap adalah menjaga aliran darah otak dan tekanan perfusi otak.
\end{abstract}

Kata kunci: Cedera kepala traumatik, tekanan intrakranial menetap, kraniektomi dekompresif

JNI 2018;7(3): 185-97

\section{Decompressive Craniectomy Management in Patients with Severe Traumatic Brain Injuries Accompanied by Refractory Intracranial Hypertension}

\begin{abstract}
Refractory intracranial hypertension is the biggest cause of death in patients with severe traumatic head injury. In severe head injuries, conservative management and surgery are performed to minimize the occurrence of secondary brain injury. The increase in intracranial pressure is usually caused by brain edema, this is very important and determines the outcomes of the Glasgow outcomes scale (GOS) or extended GOS (GOSE). Clinical data show that decompressive craniectomy reduces mortality, improves recovery function, decreases duration of ICU treatment and increases outcome outcomes based on the Barthel Index Score. Decompressive craniectomy is often performed as an empirical salvage to protect further brain damage due to the effects of edema and refractory intracranial hypertension. The main concept of managing patients with refractory intracranial hypertension is to maintain cerebral blood flow and cerebral perfusion pressure.
\end{abstract}

Key words: traumatic head injury, persistent intracranial pressure, decompressive craniectomy

JNI 2018;7(3): 185-97 


\section{Pendahuluan}

Cedera kepala merupakan penyebab kematian tersering pada trauma, data tahun 2004 dari Advance Life Trauma Support (ATLS) menunjukkan bahwa kejadian cedera kepala diperkirakan mencapai 500.000/tahun dari seluruh jumlah kasus di Amerika Serikat. Jumlah tersebut $10 \%$ meninggal sebelum sampai rumah sakit. ${ }^{1}$ Semua kasus yang sampai ke rumah sakit, sekitar $80 \%$ dikelompokkan sebagai cedera kepala ringan, $10 \%$ cedera kepala sedang dan $10 \%$ cedera kepala berat. Pada penelitian tahun 2006 menunjukkan cedera dan luka berada diurutan ke-6 dari total kasus yang masuk ke rumah sakit di seluruh Indonesia, tetapi belum terdapat data pasti mengenai jumlah cedera kepala. ${ }^{1}$ Angka kejadian tekanan tinggi intrakranial (TTIK) menetap setelah trauma adalah $15 \%$ dari seluruh pasien dengan cedera kepala traumatik. ${ }^{2}$

Data-data tersebut menunjukkan bahwa cedera kepala merupakan masalah utama kesehatan, yang biasanya disertai dengan komplikasi berupa perdarahan intrakranial, edema otak dan hidrocephalus yang akhirnya mengarah pada peningkatan TTIK. ${ }^{1-2}$ Penelitian-penelitian yang telah dilakukan selama ini, TTIK berhubungan erat dengan insedensi angka kematian dan kecacatan pasca cedera kepala. Monitoring ketat dan tatalaksana TTIK menjadi suatu hal rutin yang dilakukan di beberapa pusat trauma. Pada cedera kepala berat, tatalaksana secara konservatif dan operasi dilakukan untuk meminimalisir terjadinya cedera otak sekunder.

Peningkatan tekanan intrakranial biasanya disebabkan karena edema otak, hal ini sangat penting dan menentukan hasil luaran pasien/ Glasgow outcomes scale (GOSE) atau extended GOS (GOSE). ${ }^{1}$ Fokus tatalaksana konservatif pada edema otak yang tidak terkontrol adalah pencegahan cedera otak sekunder. Tatalaksana konservatif yang bertujuan untuk menurunkan TTIK tersebut meliputi: terapi hiperosmolar, koma barbiturat, sedasi, terapi hipotermia dan ventricular drainage. Tatalaksana konservatif tersebut terbukti efektivitasnya dalam menurunkan TTIK dengan memfasilitasi tekanan perfusi otak/cerebral perfusion pressure (CPP) dan oxygenasi (Brain Trauma Foundation 2007). ${ }^{3}$ Pada beberapa pasien terkadang tatalaksana ini tidak berhasil, dimana pembengkakan otak terjadi kontinyu dan pada akhirnya menjadi menetap, yang disebut tekanan tinggi intrakanial menetap/ refractory intracranial hypertension $(\mathrm{RICH}){ }^{2-3}$ Pada kasus-kasus seperti ini, kraniektomi dekompresif dilakukan sebagai last tier therapy dalam mengontrol tekanan intrakranial. ${ }^{4}$ Definisi kraniektomi dekompresif adalah pengangkatan sebagian area dari tulang tengkorak, yang berpotensi mempengaruhi volume kompartemen intrakranial. Kraniektomi dekompresif pertama kali dipopulerkan oleh Kocher tahun 1991 dalam tatalaksana edema otak menetap pasca trauma dibandingkan dengan terapi konservatif. Sejak saat itu, perhatian tentang hasil penelitian kraniektomi dekompresif mengalami kemajuan dan kemunduran sejalannya dengan waktu.

Walaupun masih terdapat kontroversi, kraniektomi dekompresif masih dapat dilakukan untuk menurunkan TTIK yang dihubungkan dengan kondisi klinis pasien. . $^{4}$ Prosedur kraniektomi dekompresif pertama kali digambarkan tahun 1894 oleh Annandale dan hal ini yang menuntun popularitas kraniektomi dekompresif di awal tahun 1970, yang hanya dilakukan pada pasien dengan GCS yang buruk. ${ }^{7}$ Pada waktu yang sama, penelitian-penelitian eksperimental menunjukkan bahwa kraniektomi dekompresif memperburuk edema otak dan menyebabkan prosedur operasi ini hampir dilarang untuk dilakukan.

Pada tahun 1980-an, kepopuleran kraniektomi dekompresif kembali, beberapa penelitian membuktikan bahwa kraniektomi dekompresif dihubungkan dengan TTIK yang tidak terkendali pasca trauma, selain itu juga terjadinya stroke iskemik, perdarahan subdural dan infeksi intrakranial berat. Data eksperimental menyarankan bahwa edema otak dan cedera otak sekunder dapat dilakukan kraniektomi dekompresif primer dan ini memerlukan penelitian yang lebih besar, sehingga dapat dilihat kontribusi hasilnya secara signifikan dalam menjaga tekanan perfusi otak. ${ }^{7}$ 
Selama lebih dari dua dekade ini, kraniektomi dekompresif dapat dilakukan dengan tehnik unilateral atau bilateral (bifrontally). Kraniektomi dekompresif unilateral biasanya dilakukan pada evakuasi lesi massa seperti subdural hematoma atau ketika edema otak hanya terlokalisasi pada satu hemisfer. Sedangkan, kraniektomi dekompresif bilateral biasanya dilakukan pada edema otak difus. ${ }^{1-7}$

Kraniektomi dekompresif merupakan prosedur operasi yang telah menarik perhatian para peneliti dalam tatalakasana cedera kepala berat (CKB) dengan RICH selama beberapa tahun terakhir ini. ${ }^{4}$ Kraniektomi dekompresif dapat dikategorikan menjadi primer dan sekunder. Kraniektomi dekompresif primer dilakukan pada fase akut setelah CKB, dimana pada operasi ini meninggalkan flap tulang yang sangat besar pasca evakuasi lesi di intrakranial. ${ }^{1,3-4}$ Ketika tatalaksana konservatifgagal, kraniektomi dekompresif sering dilakukan sebagai suatu tindakan penyelamatan akhir, hal ini seperti tindakan frustasi, karena pada beberapa penelitian sebelumnya menunjukkan bahwa melakukan kraniektomi dekompresif sedini mungkin menyebabkan tingginya angka kematian dan GOSE yang buruk. ${ }^{1,5}$ Pada beberapa penelitian terakhir dalam skala besar randomized controlled trial (RCTs, RESCUEicp trial) menunjukkan bahwa kraniektomi dekompresif justru dapat menurunkan TTIK dan angka kematian, meningkatkan hasil angka luaran dibandingkan dengan tatalaksana secara medis. Walau bagaimanapun, kraniektomi dekompresif sekunder masih merupakan hal kontroversial dan diperlukan penelitian lanjutan. ${ }^{5}$

\section{Edema Otak dan Tekanan Tinggi Intrakranial}

Edema otak dan TTIK adalah dasar yang paling penting dalam proses patofisiologi yang terjadi pada beberapa kondisi neurologik, seperti: perdarahan subarachnoid (SAH), cedera otak traumatik, infark otak, abnormalitas aliran darah otak (cerebral blood flow/CBF) dan asupan oksigen (oxygen delivery) yang tidak adekuat. ${ }^{6}$ Penurunan tekanan perfusi otak akan menyebabkan peningkatan tekanan intrakranial, bila hal ini berlangsung terus seperti 'lingkaran setan' yang berakhir pada kerusakan dan kematian sel. Target utama dari tatalaksana pasien-pasien seperti ini adalah memutuskan rantai 'lingkaran setan' tersebut dengan mengontrol pembengkakan otak dan mempertahankan ICP dalam batas normal. Kegagalan dalam penatalaksanaan target utama ini memberikan kontribusi yang signifikan pada GOSE buruk, angka kecacatan dan kematian tinggi pasien. ${ }^{6}$ Beberapa cara untuk menginterversi TTIK telah diaplikasikan.

Kebanyakan dari terapi ini efektif dan berhasil, seperti: penggunaan osmotik diuretik (manitol atau hipertonik saline), sedasi, barbiturat dosis tinggi, hiperventilasi ringan, hipotermia sedang, menjaga oksigenasi dan drainase cairan serebro spinal (Cerebrospinal fluid/CSF) melalui ventriculostomi. ${ }^{1,3,6}$ Bukti klinis membuktikan bahwa tidak semua tatalaksana ini berhasil dan sebagai hasilnya 'lingkaran setan' terus berlangsung. ${ }^{6}$ Pada beberapa kasus, diperlukan tatalaksana secara agresif, tetapi perlu diingat bahwa tatalaksana konservatif ini mempunyai efek samping. Pemberian manitol mempunyai efek samping, seperti: edema pulmonal, kejang, rebound hipertensi intrakranial, peningkatan tekanan intrakranial (intracranial pressurel. ICP) paradoxal, serta gangguan keseimbangan elektrolit dan cairan. Barbiturat menyebabkan hipotensi dan mendepresi fungsi jantung, sehingga terjadi peningkatan ICP rebound..$^{1,6}$ Pada keadaan-keadaan seperti ini kraniektomi dekompresif perlu dipertimbangkan sebagai pilihan terapi, dengan pemantauan ICP secara ketat. Tanda-tanda kenaikan tekanan intrakranial yang signifikan: ${ }^{8-9}$

- $20-24 \mathrm{mmHg} / 30$ menit

- $25-29 \mathrm{mmHg} / 10$ menit

- $\quad>30 \mathrm{mmHg} / 1$ menit

Tekanan tinggi intrakranial ringan: $15-25 \mathrm{mmHg}$ Tekanan tinggi intrakranial sedang: $25-40 \mathrm{mmHg}$ Tekanan tinggi intrakranial berat: $>40 \mathrm{mmHg}$

Pada tahun 2011 dilakukan penelitian secara acak kedua dengan skala yang lebih besar dan telah dipublikasikan, the DECRA study. Pelajaran utama dari penelitian decompressive cranictomy (DECRA) adalah bahwa pengurangan tekanan 


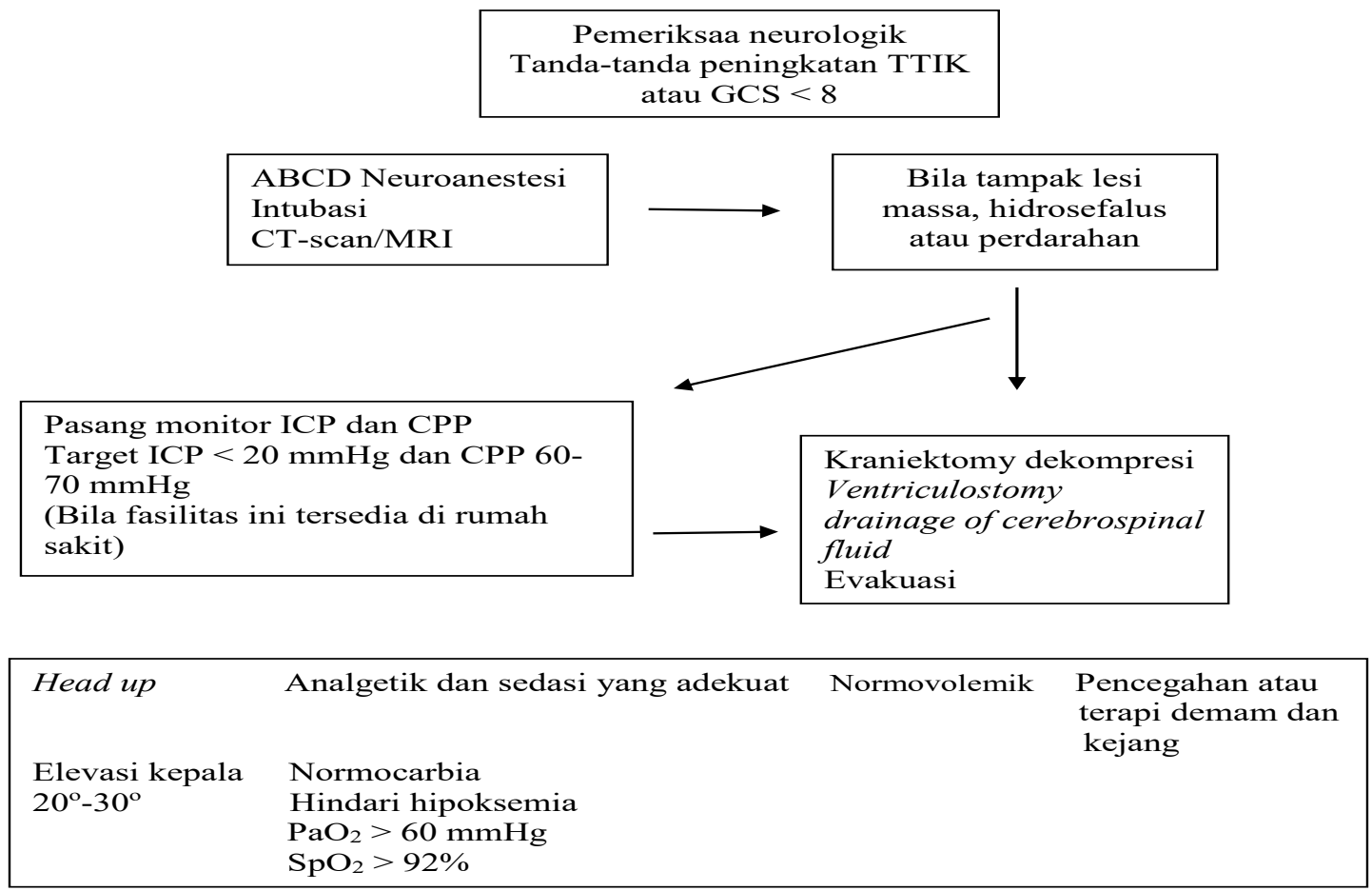

Algoritma 1. Tatalaksana Pasien dengan Cedera Kepala Traumatik ${ }^{9}$

intrakranial melalui tindakan bedah tidak selalu menghasilkan hasil yang lebih baik untuk pasien, tetapi pada beberapa pasien justru menjadi lebih buruk. $^{7}$

Pada penelitian yang dipublikasikan tahun 2012, melibatkan 155 pasien dewasa dengan cedera kepala traumatik berat, disertai dengan peningkatan tekanan intrakranial yang menetap setelah dilakukan first-tier therapy (ICP > $20 \mathrm{mmHg}$ selama $>15$ menit), yang secara acak dilakukan kraniektomi dekompresif bifrontotemporoparietal awal (indikasi: sebagai last tier therapy yang berhubungan dengan evakuasi perdarahan) atau dengan hanya tatalaksana konservatif. Pada pasien yang

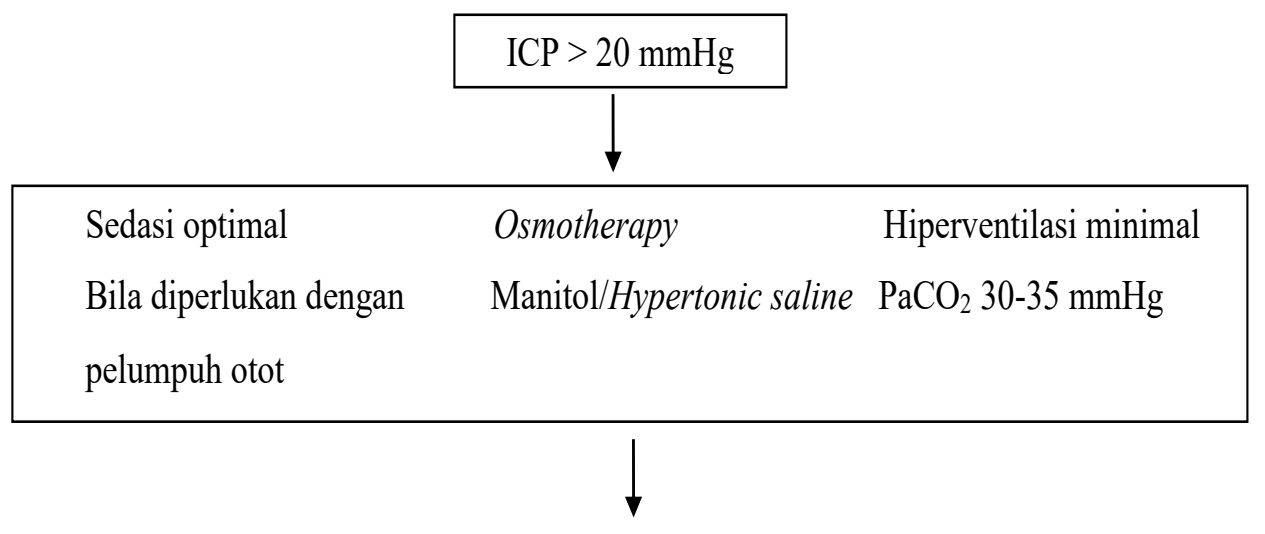

Second tier therapy

Koma barbiturate

Hipotermia sedang suhu

Hiperventilasi singkat

Kraniektomi anal: $32^{\circ}-35^{\circ} \mathrm{C}$ $\mathrm{PaCO}_{2}<30 \mathrm{mmHg}$ 


\begin{tabular}{|c|c|}
\hline \multicolumn{2}{|c|}{ Barthel Index Scoring Form } \\
\hline Rater Name: & Date: \\
\hline FEEDING & TOILET ISUE \\
\hline $0=$ unable & $0=$ dependent \\
\hline $5=$ needs help cutting, spreading butter, etc, or requires modifed diet & $5=$ needs some help, but can do something alone \\
\hline $10=$ independent & $10=$ independent (on and off, dressing, wiping) \\
\hline BATHING & TRANSFERS (BED TO CHAIR AMD BACK) \\
\hline $0=$ dependent & $0=$ unable $=$, no sitting balance \\
\hline \multirow[t]{2}{*}{$5=$ independent (or in shower) } & $5=$ major help (one or two, physical), can sit \\
\hline & $10=$ minor help (verbal or physical) \\
\hline GROOMING & $15=$ independent \\
\hline \multicolumn{2}{|l|}{$0=$ needs to help with are personal care } \\
\hline \multirow[t]{2}{*}{$5=$ independent face/hairteeth/shaving (implements provided) } & MOBILITY (ON LEVEL SURFACES) \\
\hline & $0=$ immobile or $<50$ yards \\
\hline DRESSING & $5=$ wheelchair independent, including corners, $>50$ yards \\
\hline $0=$ dependent & $\begin{array}{l}10=\text { walks with help of one person (verbal or physical) }>50 \\
\text { yards }\end{array}$ \\
\hline $5=$ needs help but can do about half unaided & $\begin{array}{l}15=\text { independent (but may use any aid; for example, stick) }>50 \\
\text { yards }\end{array}$ \\
\hline \multicolumn{2}{|l|}{$10=$ independent (including buttons, zips, laces, etc) } \\
\hline & STAIRS \\
\hline BOWELS & $0=$ unable \\
\hline $0=$ incontinent (or needs to be given enemas) & $5=$ needs help (verbal, physical, carrying aid) \\
\hline $5=0 c c a s i o n a l$ accident & $10=$ independent \\
\hline \multicolumn{2}{|l|}{$10=$ continent } \\
\hline \multicolumn{2}{|l|}{ BLADDER } \\
\hline \multicolumn{2}{|l|}{$0=$ incontinent, or catheterized and unable to manage alone } \\
\hline \multicolumn{2}{|l|}{$5=$ occasional accident } \\
\hline $10=$ continent & TOTAL SCORE $=$ \\
\hline
\end{tabular}

Gambar 1: Barthel index scoring; Total Skor yang mungkin Berkisar dari 0 - 20, dengan Skor yang Lebih Rendah menunjukkan Peningkatan Kecacatan yang Terjadi ${ }^{16}$

dilakukan kraniektomi dekompresif mengalami penurunan tekanan intrakranial lebih cepat dan mendapat perawatan lebih singkat di ICU. Beberapa dari pasien mengalami perburukan akibat komplikasi yang terjadi dan hasil luaran GOSE lebih buruk dari pasien-pasien yang hanya dilakukan tatalaksana konservatif, sehingga simpulan dari penelitian ini tidak ada perbedaan mengenai angka kematian pasien setelah 6 bulan. $^{2,12}$

\section{Kraniektomi Dekompresif}

Penelitian klinis menunjukkan bahwa kraniektomi dekompresif primer masih efektif dan aman dalam tatalaksana operasi penyelamatan pada pasien dengan TTIK yang disertai edema otak pasca cedera kepala berat. Ukuran optimal flap tulang pada kraniektomi masih merupakan controversial sampai saat ini..$^{5-8}$ Fungsi kognitif pasien dihubungkan dengan kriteria pasien dan waktu dilakukannya operasi masih merupakan kontroversi; kraniektomi dekompresif terbukti bermanfaat dalam tatalaksana pasien dengan infark massif di daerah middle cerebral artery (MCA), tidak berpengaruh kraniektomi yang dilakukan unilateral atau bilateral, dengan atau tanpa durotomi atau duroplasti. ${ }^{5-8,10}$ Seperti 
Tabel 1. Faktor-Faktor yang Mempengaruhi Hasil Luaran Kraniektomi Dekompresif pada Pasien Cedera Kepala Traumatik Berat

\begin{tabular}{|c|c|}
\hline $\begin{array}{l}\text { Tatalaksana } \\
\text { konservatif gagal }\end{array}$ & $\begin{array}{l}\text { Hipertensi intrakranial menetap yang tidak merespons strategi konservatif } \\
\text { mengakibatkan hasil luaran buruk, dengan angka kematian melebihi } 80 \% \\
\text { dilaporkan dalam beberapa seri. } \\
\text { Kraniektomi dekompresif (DC) sering dilakukan sebagai pilihan terakhir } \\
\text { dalam pengobatan seperti itu. }{ }^{16-19}\end{array}$ \\
\hline Waktu & $\begin{array}{l}\text { Kraniektomi dekompresif primer (dalam } 48 \text { jam setelah cedera) telah } \\
\text { dikaitkan dengan hasil fungsional yang baik. Laporan menunjukkan bahwa } \\
\text { pemulihan neurologis relatif lebih rendah dibadingkan dengan pasien yang } \\
\text { menjalani operasi tertunda }{ }^{10-11}\end{array}$ \\
\hline Herniasi otak & $\begin{array}{l}\text { Kraniektomi dekompresif harus dilakukan ada tanda-tanda klinis neurologis } \\
\text { herniasi otak. } \\
\text { Evaluasi pemulihan fungsional pasien, menggunakan GOSE dan Barthel } \\
\text { indeks scale menunjukkan bahwa pasien yang menjalani kraniektomi } \\
\text { dekompresif sebelum terjadinya herniasi otak memberi hasil yang relatif } \\
\text { lebih memuaskan daripada prosedur yang mereka lakukan setelah terjadi } \\
\text { herniasi otak. }{ }^{7,16}\end{array}$ \\
\hline $\begin{array}{l}\text { Glasgow coma scale } \\
\text { (GCS) }\end{array}$ & $\begin{array}{l}\text { Skor minimal harus } 8 \text {. Nilai GCS yang lebih rendah tampaknya terkait } \\
\text { dengan hasil luaran yang lebih buruk. } \\
\text { Penelitian menunjukkan bahwa terjadi peningkatan angka kematian di antara } \\
\text { pasien yang memiliki GCS } 4-6 \text { pada saat dilakukan kraniektomi dekompresif, } \\
\text { sedangkanmayoritaskorban selamatadalahmerekayangmemilikiGCS }>8 \text {. }^{7,15-20}\end{array}$ \\
\hline Usia pasien & $\begin{array}{l}\text { Harus kurang dari } 50 \text { tahun. Usia mungkin salah satu faktor kunci dalam } \\
\text { mengambil keputusan apakah akan melakukan kraniektomi dekompresif atau } \\
\text { tidak. Pasien di kelompok usia muda cenderung lebih baik setelah operasi } \\
\text { dibandingkan dengan usia lebih dari } 50 \text { tahun dikaitkan dengan hasil luaran } \\
\text { yang lebih buruk. Kejadian komplikasi juga lebih tinggi di atas usia ini. }{ }^{7,16-20}\end{array}$ \\
\hline $\begin{array}{l}\text { Kerusakan batang } \\
\text { otak primer }\end{array}$ & $\begin{array}{l}\text { Seharusnya tidak ada cedera batang otak primer. Kemungkinan angka } \\
\text { kelangsungan hidup pasien-pasien seperti ini sangat rendah dan merupakan } \\
\text { salah satu kontaindikasi dilakukannya kraniektomi dekompresif. }{ }^{15-20}\end{array}$ \\
\hline $\begin{array}{l}\text { Penemuan pupil tidak } \\
\text { normal }\end{array}$ & $\begin{array}{l}\text { Data klinis menunjukkan bahwa tidak adanya refleks pupil menunjukkan } \\
\text { hasil luaran yang sangat buruk. } .^{14-19}\end{array}$ \\
\hline Tekanan intrakranial & $\begin{array}{l}\text { Sebaiknya kurang dari } 40 \text { mmHg pada saat dilakukan kraniektomi } \\
\text { dekompresif. Data klinis menunjukkan bahwa pasien dengan ICP }>40 \\
\text { mmHg mengalami hasil luaran yang cukup buruk pasca kraniektomi } \\
\text { dekompresif dibandingkan dengan mereka yang ICP lebih rendah pada saat } \\
\text { operasi. }^{20}\end{array}$ \\
\hline Midline shift & $\begin{array}{l}\text { Tingkat pergeseran midline shift pada ct-scan awal berhubungan erat dengan } \\
\text { hasil luaran pasca kraniektomi dekompresif. } \\
\text { Pergeseran midline shift sebelum operasi }>1 \mathrm{~cm} \text { diyakini menjadi prediktor } \\
\text { signifikan dari hasil buruk. }{ }^{14-16}\end{array}$ \\
\hline
\end{tabular}

yang telah disebutkan sebelumnya, dalam 5 tahun terakhir banyak jurnal telah diterbitkan tentang manfaat, keterbatasan dan komplikasi dari kraniektomi dekompresif. Meski terdapat keterbatasan dalam metodologi penelitian, ada beberapa penelitian mengenai uji coba secara acak cedera kepala traumatik. ${ }^{5-8}$ Salah satu penelitian prospektif secara acak tahun 2001 yang dilakukan pada anak-anak (27 kasus), menunjukkan hasil yang mendukung kraniektomi dekompresif, tetapi prosedur operasi yang digunakan (dekompresif bitemporal tanpa pembukaan dura) saat ini tidak dianggap sebagai pendekatan standar. ${ }^{11}$ 


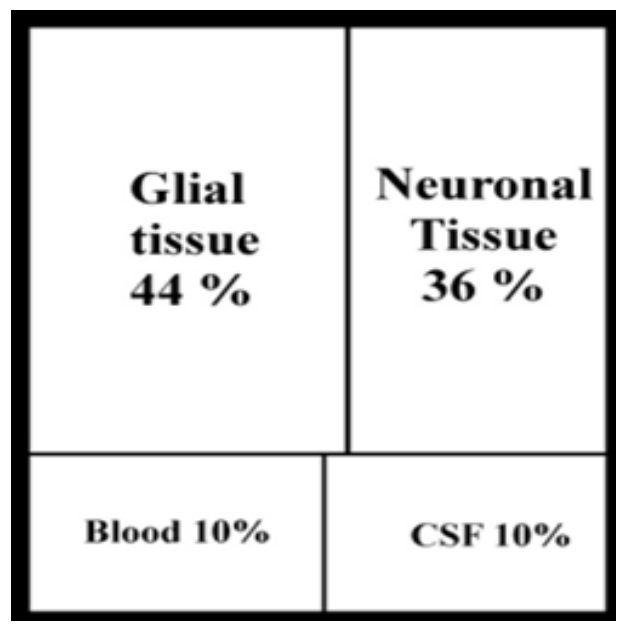

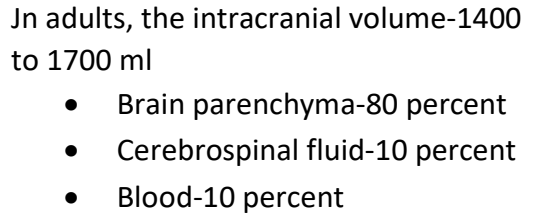

- Brain parenchyma-80 percent

- Cerebrospinal fluid-10 percent

- Blood-10 percent

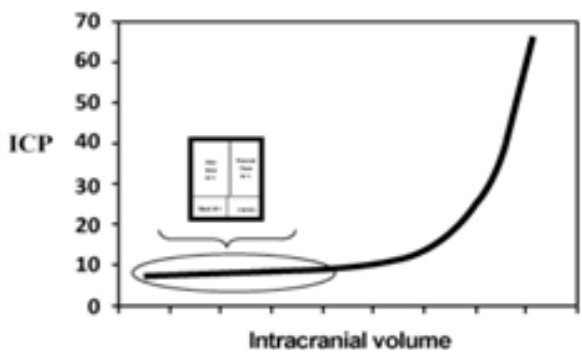

Gambar 2. Doktrin Monroe Kellie: Dalam Keadaan Fisiologis yang Normal $^{7}$
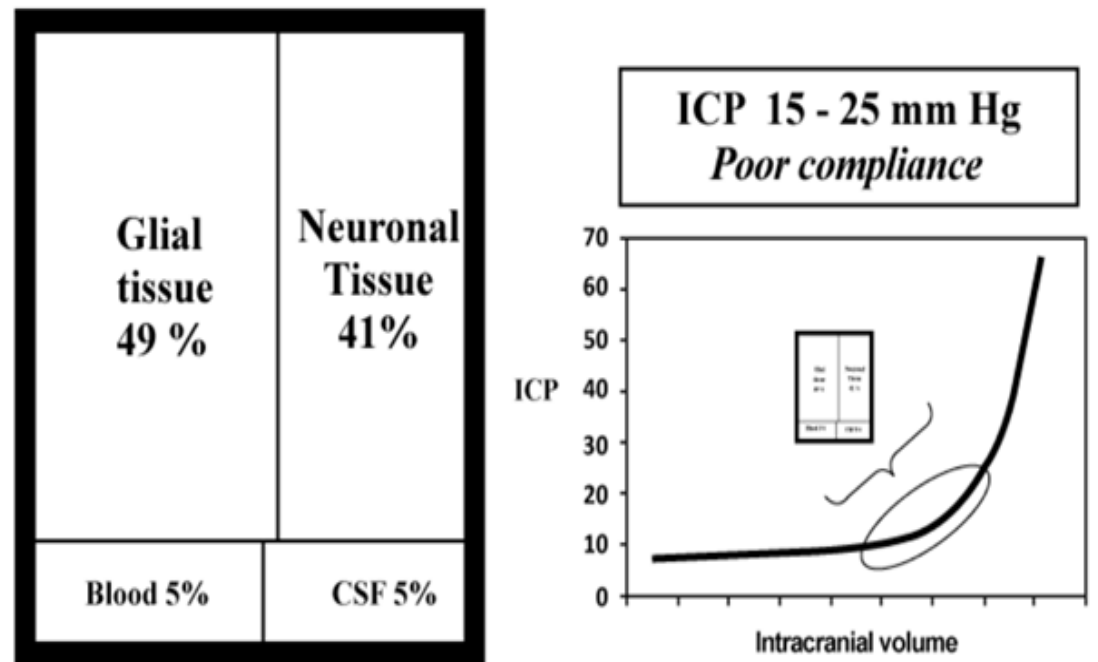

Gambar 3. Hipertensi Intrakranial dengan Kompensasi Parsial ${ }^{7}$

Penelitian prospektif terkontrol secara acak lain tentang cedera kepala traumatik berlangsung per Juni 2011, RESCUEicp. Tiga ratus Sembilan pasien dengan tatalaksana konservatif gagal mengendalikan tekanan intrakranial dengan ambang batas $25 \mathrm{mmHg}>1-12$ jam pasca cedera dipilih secara acak; evakuasi perdarahan hanya diperbolehkan sebelumpengacakan. ${ }^{13-14}$ Penelitian yang dipublikasikan tahun 2005 menunjukkan bahwa kraniektomi dekompresif dengan frontotemporoparietal yang besar (kraniektomi trauma standar) secara signifikan memperbaiki hasil luaran GOSE pasien cedera kepala berat disertai tekanan tinggi intrakranial menetap dibandingkandengankraniektomitemporoparietal rutin yang hanya memiliki efek lebih baik dalam hal penurunan tekanan intrakranial. ${ }^{14}$ Dengan segala kontroversinya, kraniektomi dekompresif terbukti masih menguntungkan dibandingkan dengan tatalaksana konservatif dalam mengontrol ICP, menjaga status neurologik dan dilakukannya penilaian status neurologik segera setelah operasi. Beberapa penelitian menunjukkan bahwa kraniektomi dekompresif meningkatkan CPP dan CBF pada pasien cedera kepala. ${ }^{15}$ Data klinis menunjukkan bahwa kraniektomi dekompresif menurunkan angka kematian, meningkatkan fungsi 

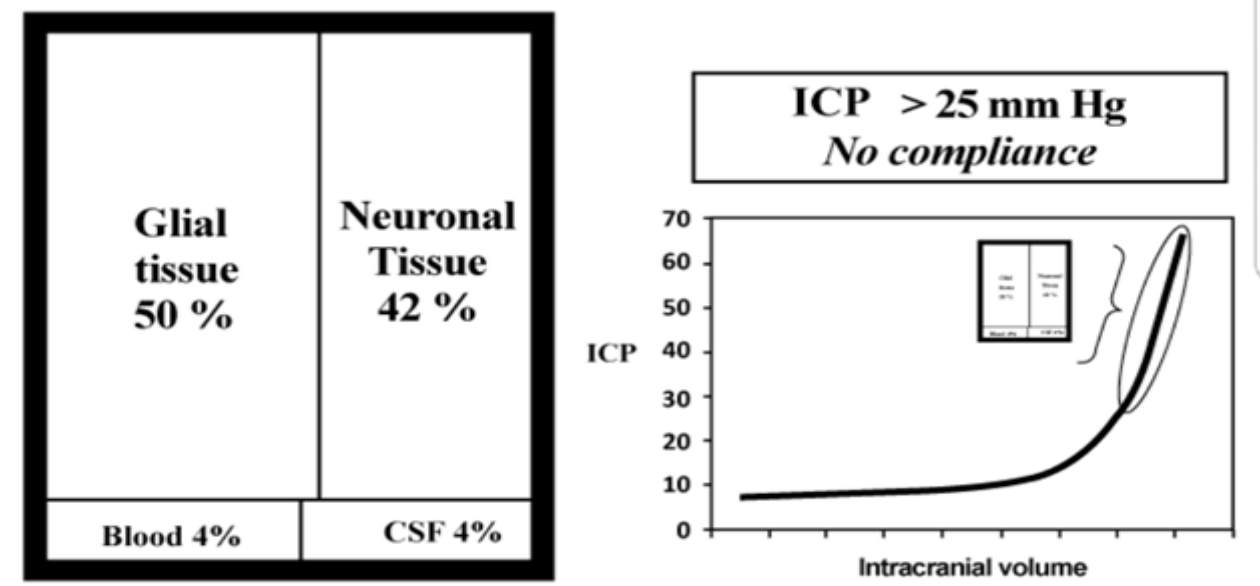

Gambar 4: Hipertensi Intrakranial Dekompensasi. ${ }^{7}$

pemulihan, menurunkan durasi perawatan di ICU dan meningkatkan hasil luaran berdasarkan Barthel Index Score (Gambar 1), ${ }^{16}$ terutama pada kraniektomi dekompresif primer. Penelitian yang dipublikasikan tahun 1999 melaporkan bahwa hampir $65 \%$ pasien-pasien mereka dengan edema otak menetap yang dilakukan kraniektomi dekompresif mengalami pemulihan cukup bagus setelah 1 tahun. ${ }^{16-17}$ Penelitian eksperimental menunjukkan bahwa pada cedera kepala traumatik dan stroke iskemik, kraniektomi dekompresif meminimalisir peningkatan ICP, memperbaiki CPP, secara signifikan menurunkan kerusakan otak sekunder, meningkatkan GOSE dan fungsi kognitif. Hal ini disebabkan karena peningkatan aliran darah kolateral, penurunan edema sel dan perbaikan oksigenasi serta metabolisme energi dalam sel. ${ }^{16-18}$

\section{Dasar Pemikiran Fisiologis untuk Kraniektomi dekompresif}

Pada tahun 1783 Monroe J. menyimpulkan bahwa tengkorak itu adalah "kotak kaku" yang diisi dengan "otak yang hampir tidak dapat dikompresi" dan volume totalnya selalu tetap konstan. Dalam keadaan fisiologis yang normal setiap peningkatan volume komponen penyusun intrakranial kompartemen tidak menyebabkan peningkatan tekanan intrakranial yang signifikan, karena adanya kompensasi volume darah atau CSF (Gambar 2). Doktrin tersebut menyatakan bahwa setiap kenaikan volume isi tengkorak (misalnya, otak, darah atau cairan serebrospinal), akan meningkatkan tekanan intrakranial. Selanjutnya, jika terjadi peningkatan volume dari salah satu dari tiga elemen ini, agar tetap konstan volumenya, otak harus mengorbankan dari dua elemen lainnya. Kellie pada tahun 1824 mengkonfirmasi banyak hasil pengamatan Monro.

Ketika terjadi cedera kepala dan otak mulai membengkak atau ada lesi massa seperti hematoma intraserebral, kompensasi dibuat dengan mengorbankan volume darah dan CSF. Hipertensi intrakranial dengan kompensasi parsial: ketika terjadi edema otak progresif kompensasi awal adalah dengan mengorbankan darah dan CSF (Gambar 3). Karena otak menjadi semakin membengkak atau lesi massa meningkat dalam ukuran, terjadi mekanisme dekompensasi dan akibatnya ketika kenaikan volume yang sedikit lebih kecil terjadi mengakibatkan peningkatan tekanan intrakranial yang menetap. ketika edema otak semakin memburuk atau membesarnya lesi massa terjadi pada saat mekanisme kompesasi mulai gagal, sehingga ketika terjadi peningkatan pembengkakan sedikit saja, maka tekanan intrakranial meningkat secara drastis (Gambar 4). ${ }^{7}$ Otak secara anatomi dibagi menjadi falx cerebri dan tentorium cerebri. Peningkatan tekanan intracranial sering menghasilkan penekanan gradien di antara kompartemen dan memungkinkan terjadinya herniasi otak. ${ }^{7,10-20}$ 
Peningkatan tekanan intrakranial dapat terjadi secara akut atau bertahap. Banyak sindrom klinis tekanan tinggi intrakranial yang terjadi merupakan konsekuensi dari kecepatan perubahan dari kompartemen otak, bukan tingkat absolut tingginya tekanan otak. Ada tiga jenis herniasi otak: transtentorial (baik lateral atau pusat), tonsillar, dan subfalcine. Pasien dengan tekanan intrakranial tinggi dapat terlihat dari gejala neurologis, mulai dari mengantuk/somnolen sampai koma yang dinilai dengan Glasgow Coma Score (GCS) biasa terjadi.

Kelainan posisi tubuh pasien bisa menujukkan kelainan yang terjadi, baik secara motorik maupun sensorik. Herniasi dari uncus lobus temporal antara batang otak dan tepi tentorial ke dalam fossa posterior mengakibatkan gangguan kesadaran yang progresif, pupil ipsilateral yang melebar, dan hemiplegia kontralateral. Herniasi dari cerebellum melalui foramen magnum hingga bagian atas saluran tulang belakang yang mengkompresi medulla akan menimbulkan gangguan kardiopulmonal, hipertensi, tekanan nadi tinggi, pernapasan Cheynes-Stoke, hiperventilasi neurogenik, gangguan kesadaran, dan kematian. ${ }^{7,9,11}$

Mempertahankan perfusi otak yang optimal pada periode akut setelah cedera kepala traumatis adalah tujuan utama manajemen yang diarahkan untuk mencegah cedera otak iskemik sekunder. Tekanan perfusi otak yang dihitung sebagai tekanan darah arterial rerata/mean arterial pressure (MAP) dikurangi tekanan intrakranial rerata (ICP), adalah parameter yang relevan secara klinis yang mencerminkan kekuatan pendorong substrat darah dan metabolik ke sel otak. Tekanan perfusi otak yang tidak memadai terkait dengan hasil neurologis yang tidak menguntungkan namun telah terjadi perdebatan mengenai tingkat optimal untuk mempertahankan tekanan perfusi otak. Bukti terbaru telah menghasilkan revisi Pedoman Pengelolaan Cedera Otak Parah pada orang dewasa untuk merekomendasikan mempertahankan tekanan perfusi otak minimum $60 \mathrm{mmHg}$, turun dari $70 \mathrm{mmHg}$ pada pedoman sebelumnya. $1,4,7,9,20$
Bila dilihat dari sudut pandang ini keterbatasan, tatalaksana konservatif, seperti: hiperventilasi, koma barbiturat dan lain lain ini bisa diapresiasi. Ada sedikit keraguan bahwa barbiturat dan hipotermia berpotensi menjadi neuroprotektif karena pengaruhnya terhadap banyak mekanisme yang diketahui penting dalam respons seluler terhadap cedera seperti toksisitas yang dimediasi kalsium, ekskotoksisitas glutamat, peroksidasi radikal bebas dan apoptosis seluler. Penurunan tekanan intrakranial yang sering terjadi setelah penerapan salah satu dari tiga terapi ini terjadi sebagai akibat vasokonstriksi otak. Mengingat efek iskemia yang sering terjadi, mungkin tidak mengherankan bahwa banyak penelitian telah gagal menunjukkan bahwa terapi ini memberikan manfaat klinis dalam hal perbaikan dalam hasil jangka panjang. Di sinilah kraniektomi dekompresif mungkin paling tidak memiliki keuntungan teoritis. Dengan Doktrin Monroe Kellie sebagai pedoman dalam memperluas "kotak kaku", tekanan tinggi intrakranial dapat dikurangi, namun tidak dengan mengorbankan volume darah serebral, sehingga tekanan perfusi otak tampaknya akan meningkat. ${ }^{7-10}$

\section{Indikasi dan Kontraindikasi Kraniektomi Dekompresif}

Secara keseluruhan, tidak ada indikasi mutlak untuk kraniektomi dekompresif. Indikasi untuk hemikraniektomi dekompresif adalah lesi unilateral, seperti: edema otak unilateral, kontusio otak/contusion cerebri, perdarahan epidural atau subdural, gambaran CT-scan menunjukkan midline shift. Dekompresif bifrontal dilakukan bila ada edema serebral difus tanpa pergeseran midline shift yang jelas. ${ }^{14-20}$ Berdasarkan konsorsium European Brain Injury dan pedoman Brain Trauma Foundation berkaitan dengan cedera kepala traumatik berat, seharusnya kraniektomi dekompresif dimasukkan dalam second tier therapy, pada pasien dengan peningkatan TTIK menetap yang tidak berhasil dengan tatalaksana secara konservatif, maka tindakan operasi merupakan pilihan., ${ }^{214-20}$ Waktu terbaik untuk dilakukan kraniektomi dekompresif masih menjadi kontroversi. Kraniektomi dekompresif primer (dalam waktu 24 jam setelahnya cedera) 
dianjurkan pada pasien dengan cedera kepala berat tanpa disfungsi batang otak untuk mengurangi tekanan tinggi intrakranial. Beberapa penelitian menunjukkan bahwa kraniektomi dekompresif primer dapat mengurangi komplikasi akibat cedera kepala traumatik. ${ }^{15-20}$

Keputusan dilakukan tindakan operasi dapat berdasarkan pada beberapa hal, yaitu: pada mekanisme cedera pasien; usia; tingkat tekanan intrakranial, terjadinya iskemia otak dan perkiraan ahli bedah saraf tentang kemungkinan pasien akan mengalami peningkatan TTIK yang berat. Dengan pemantuan tekanan intrakranial yang ketat, seharusnya kraniektomi dekompresif bisa menjadi pilihan tatalaksana untuk mencegah otak herniasi. Jika tidak, hasil dari pasien yang menjalani kraniektomi dekompresif sekunder (setelah 24 jam) cukup memuaskan. ${ }^{7-15}$

Kontraindikasi dilakukannya kraniektomi dekompresif menurut kajian penelitian yang dipublikasikan tahun 2009, adalah: ${ }^{17}$ pasien dengan GCS 3 pasca resusitasi, dengan pupil yang melebar dan tetap, pasien $>65$ tahun, trauma yang tidak akan memungkinkan pasien bertahan lebih dari 24 jam, pasien dengan penyakit sistemik yang ireversibel, TTIK yang tidak terkendali selama lebih dari 12 jam setelah tatalaksana konservatif gagal, perbedaan arterio-vena $\mathrm{O}_{2}<3,2$ vol\%, diukur di sisi hemikraniektomi atau $\mathrm{PtiO}_{2}<10$ $\mathrm{mmHg}$ di daerah yang sehat sejak pasien tiba di rumah sakit.

\section{Komplikasi Kraniektomi Dekompresif}

Komplikasi pertama yang mungkin terjadi adalah perluasan dari lesi perdarahan, diikuti dengan munculnya perdarahan subdural baru pada sisi kontralateral, kejang, kebocoran CSF, dan herniasi otak. Beberapa komplikasi bisa berakibat fatal, seperti: infeksi intrakranial dan perdarahan intrakranial kontralateral, sementara yang lainnya dapat mempengaruhi neurologis dan pemulihan fungsi kognitif pasien. Komplikasi lebih sering terjadi pada pasien dengan GCS rendah dan berusia $>60$ tahun saat tiba di rumah sakit. Penelitian yang dipublikasikan tahun 2006 menyatakan hampir 50\% pasien memiliki setidaknya satu komplikasi, meskipun situasi ini terkadang sembuh secara spontan tanpa intervensi bedah lanjutan..$^{8,9,12,14}$ Peningkatan faktor resiko terjadinya infeksi dan memerlukan perluasan defek termasuk, pengangkatan bola mata, sehingga angka kecacatan tinggi. Operasi rekontruksi lanjutan memberikan hasil yang cukup memuaskan. ${ }^{15-20}$

Herniasi melalui defek kraniektomi, terjadi pada $27,8 \%$ pasien, kraniektomi dekompresif seluas mungkin diharapkan dapt mencegah terjadinya hal ini. Kraniektomi dekompresif digabungkan dengan augmentative duraplasti akan mencapai efek dekompresi yang serupa, dibandingkan dengan meninggalkan dura terbuka, dan akan sangat membantu dalam mencegahnya herniasi melalui defek tengkorak yang dibatasi cephalocoele. ${ }^{15-20}$ Efusi subdural terjadi hampir $21,3 \%$, mungkin karena gangguan CSF yang berasal dari dekompresif kraniektomi sendiri. Efusi subdural kontralateral disebabkan oleh kraniektomi dekompresif jarang dilaporkan, hal ini mungkin disebabkan karena pola aliran CSF pada tekanan intrakranial yang rendah. Komplikasi ini biasanya berhubungan dengan neurologis pasca operasi akibat penurunan atau peningkatan ICP. Faktor risiko efusi subdural setelah trauma kepala meliputi: pendarahan subarachnoid, penyusutan otak karena retraksi selama intraoperatif dan pergeseran jaringan otak secara signifikan. Komplikasi ini mungkin perlu penanganan yang lebih agresif karena kecenderungan untuk menyebabkan pergeseran midline shift. ${ }^{15-20}$

Hidrosefalus pasca-trauma, berkisar hingga 9,3\%; karena pasien yang cedera tidak dapat menunjukkan gejala klinis, CT-scan bisa sangat berguna untuk deteksi pasien dengan dilatasi atau pergeseran ventrikel otak. Baru-baru ini, hidrosefalus komunikan merupakan komplikasi yang sering terjadi setelah hemikraniektomi dan kranioplasti awal. Penelitian yang dipublikasikan tahun 2010 justru menyatakan bahwa hidrosefalus tidak sering terjadi setelah kraniektomi dekompresif. Beberapa faktor resiko terjadinya hidrosefalus komunikan pada pasien dengan peningkatan TTIK, seperti: usia tua, pendarahan 
subaracnoid, infeksi CSF, GCS rendah dan luas tutup kraniektomi. Kraniektomi dengan batas atas $<25 \mathrm{~mm}$ ke midline shift merupakan salah satu predisposisi terjadinya hidrosefalus juga. Shunting jelas diperlukan saat tekanan CSF lumbal secara konsisten $>180 \mathrm{mmH}_{2} \mathrm{O}$ atau gejala khas hidrosefalus ada, kecuali ada kontraindikasi pembedahan. ${ }^{16-20}$

Syndrome of trephined, sangat jarang, klinis manifestasi meliputi: sakit kepala, pusing, lekas marah, epilepsy dan gangguan kejiwaan. Sindrom ini terutama berkaitan dengan defek kraniektomi yang sangat besar. Perbaikan penutupan defek kepala dalam 8 minggu setelah kraniektomi, tetapi pada pasien cedera kepala traumatik yang dilakukan cranioplasty awal dapat meningkatkan risiko infeksi, sehingga hal ini tidak disarankan. ${ }^{14}$ Hematoma kontralateral setelah kraniektomi dekompresif terjadi sampai 7,4\%. Hal ini tidak biasa terjadi dan dikaitkan dengan peningkatan angka kematian yang signifikan. Pengurangan tekanan intrakranial setelah kraniektomi dekompresif dianggap sebagai alasan penting dalam susunan kompartemen isi kepala, sehingga perdarahan jauh dari lokasi operasi. Kunci utama dalam tatalaksana komplikasi ini adalah deteksi dini dan operasi ulangan. ${ }^{20}$

\section{Prognosis}

Usia pasien dengan cedera kepala traumatik merupakan salah satu faktor penentu prognostik. Sebagian besar penelitian retrospektif dan prospektif yang telah dilakukan sayangnya memiliki batas usia $60-65$ tahun..$^{20-21}$ Penelitian yang dipublikasikan tahun 2009 mengambil sampel dengan rentang usia yang lebih luas (15-90 tahun), rata-rata pasien dengan hasil luaran yang baik secara signifikan adalah berusia muda. ${ }^{17-21}$ Laporan serial kasus dalam publikasi tahun 2002 menyatakan bahwa sebagai faktor prognostik paling penting sejauh ini umur. Hanya $7 \%$ pasien berusia di atas 65 tahun dengan hasil luaran yang baik, angka kematian setelah 6 bulan sebesar $72 \%$. Pernyataan ini mirip dengan penelitian yang dipublikasikan tahun 2011, yang menyatakan angka kematian pasien sebesar $77 \%$ setelah 1 tahun, untuk sampel sebanyak 44 pasien cedera kepala traumatik yang dilakukan kraniektomi dekompresif dengan usia $>65$ tahun. ${ }^{12}$

Penelitian yang dipublikasikan tahun 2012 menujukkan bahwa tidak ada korelasi antara usia dengan hasil luaran pasien. Ukuran flap tulang yang memadai adalah faktor lain yang terkait kelangsungan hidup. Besar flap tulang (lebih besar dari $12 \mathrm{~cm}$ ) berhubungan dengan angka kelangsungan hidup hanya pada pasien yang berusia di bawah 65 tahun. Penelitian menunjukkan bahwa pasien dengan flap tulang ukuran besar juga memiliki hasil luaran yang lebih baik. Dua pertiga dari pasien dengan flap tulang $>12 \mathrm{~cm}$ telah dilaporkan berhasil dan memiliki hasil luaran yang bagus, sedangkan angka kematian $<20 \%{ }^{7}$

\section{Simpulan}

Kraniektomi dekompresif sangat efesien dalam menurunkan tekanan intrakranial menetap. Tidak semua pasien yang mengalami peningkatan tekanan intrakranial dapat dilakukan kraniektomi dekompresif. Faktorfaktor yang menjadi bahan pertimbangan adalah faktor usia, tingkat kesadaran pasien sebelum dilakukan operasi, ukuran flap tulang yang efektif dan waktu yang tepat untuk dilakukan. Dengan segala kontroversinya, kraniektomi dekompresif terbukti masih menguntungkan dibandingkan dengan tatalaksana konservatif dalam mengontrol ICP, menjaga status neurologik dan dilakukannya penilaian status neurologik segera setelah operasi.

\section{Daftar Pustaka}

1. Grindlinger GA, Skavdahl DH, Ecker RD, Sanborn MR. Decompressive craniectomy for severe traumatic brain injury: clinical study, literature review and meta-analysis. Springerplus 2016; 5 (1605): 1-12.

2. Hutchinson PJ, Kolias AG, Timofeev IS, Corten EA, Czosnyka M, Timithy J, dkk. Trial of decompressive craniectomy for traumatic intracranial hypertension. N Engl J 
Med 2016: 375 (12): 1119-30.

3. Carney N, Totten AM, O'Reilly C, Ulman JS, Hawryluk GWJ, Bell MJ, Bratton SL, dkk. Guidelines for management of severe traumatic brain injury, Edisi ke-4. Neurosurgery 2016; 0 (0): 1-10.

4. Cooper DJ, Rosenfeld JV, Murray LM, Arabi YM, Davies AR, D'Urso P, Kossmann T, dkk. Decompressive craniectomy in diffuse traumatic brain injury. N Eng J Med 2011; 16 (364); 1493-502.

5. Zhang D, Xue Q, Chen J, Dong Y, Hou L, Jiang Y, Wang J. Decompressive craniectomy in the management of intrakranial hypertension after traumatic brain injury: a systematic review and meta-analysis. Scientific Report 2017; 7; 1-10.

6. Eghwrudjakpor PO, Allison AB. Decompressive craniectomy following brain injury: factors important to patient outcome. Libyan J Med 2010; 5: 4620-26.

7. Honeybul S. Decompressive craniectomy for severe traumatic brain injury: a review of its current status. J Neurol Neurophysiol 2012; 3 (7): $1-6$.

8. Rahmanian A, Seifzadeh B, Razmkon A, Petramfar P, Kivelev J, Hernesniemi J. Outcome of decompressive craniectomy in comparison to nonsurgical treatment in patients with malignant MCA infarction. Springerplus 2014; 3 (1): 115-21

9. Servadei F. Clinical value of decompressive craniectomy. N Engl J Med 2011; 364 (16): 1558-9

10. Tagliaferri F, Zani G, Iaccarino C, Ferro S, Ridolfi L, Basaglia N, dkk. Decompressive cranictomies, facts and fiction: retrospective analysis of 526 cases. Acta Neuro (Wien) 2012; 154 (5): 919-26

11. Jiang JY, Xu W,Li WP, Xu WH, Zhang J,
Bao YH, dkk. Efficacy of standard trauma craniectomy for refractory intracranial hypertension with severe traumatic brain injury: a multicenter, prospective, randomized control study. J Neurotrauma 2005; 22 (6): 623-8

12. Zweeckbergeer K, Stoffel M, Baethmann A, Plesnila N. Effect of decompression craniotomy on increase of contusion volume and functional outcome after controlled cortical impact in mice. J Neurotrauma 2003; 20:1307-4.

13. Van Veen E, Aerdts S, van den Brink W. decompressive (hemi)cranictomy for refractory intracranial hypertension after traumatic brain injury. Critical Care 2006; 10: 458-63.

14. Bullock MR, Chesnut R, Ghajar J, Gordon D, Hartl R, Newell DW, dkk. Surgical management of traumatic parenchymal lesions. Neurosurgery 2006; 58: 25-46.

15. Mori K, Nakao Y, Yamamoto T, Maeda M. Early external decompressive craniectomy with duroplasty improves functional recovery in patients with massive hemispheric embolic infarction: timing and indication of decompressive surgery for malignant cerebral infarction. Surg Neurol. 2004; 62: 420-30.

16. Ziai WC, Port JD, Cowan JA, Garonzik IM, Bhardwaj A, Rigamonti D. Decompressive craniectomy for intractable cerebral oedema: experience of a single centre. J Neurosurg Anaesthesiol. 2003; 15: 25-32.

17. Meier U, Lemcke J, Reyer T, Grawe A. Decompressive craniectomy for severe head injury in patients with major extracranial injuries. Acta Neurochir 2006; 96: 373-6.

18. National Trauma Research Institute, Australia. The DECRA trial: early decompressive craniectomy in patients with severe traumatic brain injury; 2009. Available from: http:// clinicaltrials.gov/show/NCT00155987 [cited 
27 September 2009].

19. Raslan A, Bhardwaj A. Medical management of cerebral edema. Neurosurg Focus 2007; 22 (5): 1-12.
20. Santana-Cabrera L, Pérez-Acosta G, Rodríguez-Escot C, Lorenzo, Torrent $\mathrm{R}$, Sánchez-Palacios M. Complications of postinjury decompressive craniectomy. Int J Crit Illn Inj Sci 2012; 2 (3): 186-8. 